\title{
ESTIMATION OF FETAL BIRTH WEIGHT USING ULTRA SONOGRAPHIC PARAMETERS
}

\begin{abstract}
:
One hundred antenatal patients were studied at term pregnancy at Gauhati Medical College, Guwahati, and fetal birth weight estimation was done in utero Ultrasono-graphically. The parameters measured were Abdominal Circumference (AC), Biparietal diameter (BPD) and Femur Length (FL), Fetal weight prediction was done with Shepards formula using AC and BPD as well as Hadlocks formula using FL and AC. The scan delivery interval was maintained at 72 hours or less. Results of both formulae were compared with the actual fetal birthweight taken within 15 minutes of delivery. With Shepards formula, the predicted fetal weight was within $100 \mathrm{gm}$ of the actual fetal weight in $71 \%$ cases, within $150 \mathrm{gm}$ in $86 \%$ cases, within $200 \mathrm{gms}$ in $93 \%$ cases and within $250 \mathrm{gms}$ in $98 \%$. With Hadlocks formula, the predicted birthweight was within $100 \mathrm{gms}$ of the actual fetal weight in $72 \%$ cases, within $150 \mathrm{gms}$ in $83 \%$, within $200 \mathrm{gms}$ in $92 \%$ cases and within $300 \mathrm{gms}$ in $98 \%$. The mean percent error calculated as Error $\%=$ Predicted weight - actual weight divided by actual weight x 100 was $2.9 \%$ with Shepards formula and 3\% with Hadlocks. These data thus support a significant correlation between ultrasonographic estimation and actual fetal birth weight.
\end{abstract}

Key Words: Fetal birth weight, AC, BPD, FL

\section{INTRODUCTION:}

The assesment of fetal birthweight forms an important part of prenatal care. The clinical management, the outcome of pregnancy, delivery and survival of the newborn are greatly influenced by the knowledge of fetal weight Accurate determination of fetal weight prior to delivery can have a significant bearing on management decisions in labour, thereby markedly improving perinatal outcome. The route of delivery is also influenced by the size of the baby. Knowledge of fetal by the most suitable route. Fetuses weighting more than $3.5 \mathrm{~kg}$., if presenting by the podalic extremity will be better managed by delivery via the abdominal route. Similarly in a case of multifetal pregnancy with gross discordance in fetal sizes, where the much smaller twin presents as the first candidate for delivery, one may opt for a caesarian section.

Various clinical methods for fetal weight estimation have now been surpassed by the more accurate ultrasonographic measurements. Various parameters like Abdominal Circumference, Biparietal diameter, Femur length and Head circumference are used. In our study three sonographic parameters were used in an attempt to estimate fetal weight. There were

Biparietal diameter - as an index of head size

Abdominal circumference - as an index of body size

Femur Length - as an index of crown heel length

\section{MATERIAL AND METHODS:}

100 antenatal cases were selected randomly from the local population, admitted to Gauhati Medical College Hospital for delivery and scanned ultra-sonographically. Three parameters BPD, AC and FL were studied. Only full term pregnancies were included in the study. Cases were selected irrespective of associated complications like diabetes, pregnancy induced hypertension, I.U.G.R. etc. The scan-delivery interval was maintained at 72 hours or less. Fetuses suspected of having dolicho cephaly (cephalic index less than 70) or brachy cephaly (cephalic index more than 86 ) were excluded from the study. 
$\mathrm{BPD}^{1}$ was measured as the largest diameter between the outer and inner skull tables at right angle tot he falx at a plane slightly above and parallel to the canthomeatal line which includes the falx, thalamus, septum pellucidum and an oval head shape. Abdominal Circumferenc ${ }^{2,3}$ measurement was obtained in the transverse plane perpendicular to the long axis of the fetal aorta or spine at the portoumbilical vein complex within the liver. Femur Length ${ }^{4}$ was measured as the linear distance between the greater trochanter of the femur to the distal metaphysis. All measurements were made in millimeters and an average of three reading taken. Estimation of fetal weight was done using two formulae.

Shepard's - Estimated fetal wt EFW:

Hadlock's -

$$
\log 10(\mathrm{BW})=-1.7492+0.166(\mathrm{BPD})+0.046(\mathrm{AC})-2.646(\mathrm{AC}+\mathrm{BPD}) / 1000
$$

EFW: $\log 10(\mathrm{BW})=1.3598+0.051(\mathrm{AC})+0.1844(\mathrm{FL})-0.0037(\mathrm{AC} \times \mathrm{FL})$

\section{RESULTS AND OBSERVATIONS:}

The actual birthweights ranged from 2000-4200 gms with a mean of 2739 gms. Using Shepards formula the estimated birth weights ranged from 2089-4050 gms with a mean of 2716 gms. Hadlocks formula estimated a range of 1847-4145 gms with a mean of $2713 \mathrm{gms}$.

The predicted fetal weight was within 100 gms of actual weight in $71 \%$ cases, within 150 gms in $86 \%$ cases, within $200 \mathrm{gms}$ in $93 \%$ and $250 \mathrm{gms}$ in $98 \%$ with Shepards formula. Using Hadlocks formula the results were within 100 gms of actual weight in $72 \%$ cases, within 150 gms in $83 \%$, within 200 gms in $92 \%$ and within 300 gms in $98 \%$ cases.

Table I showing range of predictability in relation to actual weight with both formulae.

\begin{tabular}{|c|c|c|}
\hline $\begin{array}{c}\text { Predictability } \\
\text { within gms }\end{array}$ & $\begin{array}{c}\text { Shepard's 'No of } \\
\text { cases' }\end{array}$ & $\begin{array}{c}\text { Hadlocks 'No of } \\
\text { cases' }\end{array}$ \\
\hline \pm 50 & 45 & 41 \\
\hline \pm 100 & 71 & 72 \\
\hline \pm 150 & 86 & 83 \\
\hline \pm 200 & 93 & 92 \\
\hline \pm 250 & 98 & 96 \\
\hline \pm 300 & 100 & 98 \\
\hline \pm 350 & - & 99 \\
\hline \pm 450 & - & 100 \\
\hline
\end{tabular}

Table II showing difference between estimated birth weight and actual birth weight in 3 different weight categories.

\begin{tabular}{|c|c|c|c|c|c|}
\hline $\begin{array}{c}\text { Actual birth weight } \\
\text { in gms }\end{array}$ & $\begin{array}{c}\text { No. of } \\
\text { cases }\end{array}$ & \multicolumn{2}{|c|}{$\begin{array}{c}\text { Absolute difference in gms. } \\
\text { Mean } \pm \text { SD }\end{array}$} & \multicolumn{2}{c|}{ Mean \% error } \\
\hline & & Hadlock's & Shepard's & Hadlock's & Shepard's \\
\hline$<2500$ & 26 & $111.6 \pm 86.55$ & $65.04 \pm 59.8$ & 4.6 & 2.8 \\
\hline $2501-3000$ & 72 & $77.2 \pm 72.2$ & $83.69 \pm 65.9$ & 2.6 & 3 \\
\hline
\end{tabular}


The ' $t$ ' test was performed to determine the statistical significance of the difference between estimated weight and actual weight. With both formulae, $\mathrm{t}=0.78, \mathrm{p}>0.05$ which is not significant. The implies a significant correlation between actual and estimated weights.

\section{DISCUSSION:}

The estimation of fetal weight in utero is an important factor in the management of pregnancy, more so in high risk pregnancies. As such numerous studies have been conducted in an attempt to predict fetal weight ultra-sonographically. Our study showed comparable results to some of these.

Hill $^{5}$ et al in 1985 using Shepard's model of Ac and BPD reported 50\% of the estimated weight within 225 gms and 90\% within 605 gms. Gulati ${ }^{6}$ et al in 1989 estimated $72 \%$ cases within 150 gms. In our study $70 \%$ of the estimates were within $100 \mathrm{gms}$ and $85 \%$ within $150 \mathrm{gms}$ which is comparable to the above study. Shepard et $\mathrm{al}^{7}$ in 1982 obtained a mean \% error of 3.5\%. In our study using Shepard's model the mean percent error was $2.9 \%$ and with Hadlocks model it was $3 \%$. In this study both formulae were found to the equally applicable to the population. The accuracy of a combined BPD/AC model which involves both measurements of the fetal head and trunk in which most of the fetal mass lies has been confirmed by most authors. Hadlock's ${ }^{8}$ model based on AC \& FL is equally comparable. This is due to the strong linear relationship of femur length to crown heel length. In cases where the BPD may prove to be unreliable as a parameter as in dolichocephaly / brachycephaly, or when the deeply engaged head prevents accurate measurement, Hadlocks model will prove to be extremely useful.

\section{CONCLUSION:}

This study supports a significant correlation between the ultrasound estimate of fetal weight and actual fetal birth weight. Both the formulae have shown a comparable accuracy in predicting expected fetal weight. In some cases where the head is deeply engaged and it is difficult to measure BPD, Hadlock's formula may be used. Accurate estimation of fetal weight particularly in high risk pregnancies should be encouraged to ensure a better obstetric ultrasound reports.

\section{REFERENCES:}

1. Campbell S — Jr Obs \& Gynae Brit. C' wealth 75: 568-576 (1986)

2. Hadlock F.P., Harrist R.B., Carpenter R.J. — Jr. Radio: 150: 535-540 (1984)

3. Campbell S, Dewhurst C.J. — Lancet: 2: 1002 (1971)

4. Campbell S, - Clinics in perinatalogy - 1: 507-525 (1974)

5. Hill LM, Brecke, Gehrking WC — Am Jr. Obs. Gynae 152: 847-852 (1985)

6. Gulati N, Sharma TB Sharma V.K. — Jr. obs, Gynae 39: 155-158 (1989)

7. Shepard M.J., Richard V.A., Warsof S.C. - Am. Jr. Obs. gynae 147: 47-54 (1982)

8. Hadlock P, Frank, Harrist R.BI. - Am Jr. Obs. Gynae 151: 333-337 (1985) 